\title{
THE JANUARY 2002 ERUPTION OF NYIRAGONGO VOLCANO (DRC) CAPTURED BY INSAR
}

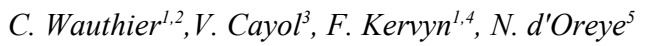 \\ ${ }^{1}$ Dept. of Geology, Royal Museum for Central Africa, 3080 Tervuren, Belgium, christelle.wauthier@africamuseum.be $/{ }^{2}$ Dept. ArGEnCo, \\ University of Liège, Sart Tilman B52, 4000 Liège, Belgium $/{ }^{3}$ Lab. Magmas et Volcans, Univ. Blaise Pascal - UMR 6524, 63038 \\ Clermont-Ferrand, France $/{ }^{4}$ Centre d'Informations Géographiques SODERU, Goma, DRC $/{ }^{5}$ Dept. of Geophysics/Astrophysics, National \\ Museum of Natural History, 7256 Walferdange, Luxembourg.
}

\begin{abstract}
On $17^{\text {th }}$ January 2002 , Nyiragongo erupted along an approximately $20 \mathrm{~km}$ long fracture network extending from the volcano to the city of Goma and its airport. The event was captured by InSAR data from the ERS-2 and RADARSAT-1 satellites acquired in three different geometries. These data show complex ground displacements, with several overlapping fringe patterns, associated to a combination of sources of magmatic and tectonics origins. A combination of $3 \mathrm{D}$ numerical modeling and inversions is used in order to interpret these displacements. Synthetic tests indicate that with one to three INSAR geometries, the best fit and mean models are within the confidence intervals whether the source of displacements is a single dike, a dike combined with a west dipping normal fault or a dike combined with an ellipsoid. Increasing the number of InSAR geometries makes the confidence intervals smaller and the inversions faster. At this stage of the study, only the area close to the eruptive fissures was analyzed assuming displacements were caused by a single dike. The best-fit dike model obtained with a simultaneous inversion of the three InSAR geometries is subvertical, and has a low overpressure. Both characteristics are consistent with the rift context.
\end{abstract}

Index Terms - Nyiragongo, East African Rift, Radar interferometry, modeling.

\section{INTRODUCTION}

With Nyamulagira, Nyiragongo is one of the two active volcanoes of North Kivu (Democratic Republic of Congo). It is located in the western branch of the East African rift (EAF). This area is affected by a combination of seismic and volcanic activities [1]. On $17^{\text {th }}$ January 2002, Nyiragongo erupted along an approximately $20 \mathrm{~km}$ long fracture network extending from the volcano to the city of Goma [2]. Two lava flows entered the town and destroyed about $15 \%$ of it. Seismic activity was high during the eruption, with about 20 earthquakes recorded in USGC catalogue $(\mathrm{mb}>4)$. An increase of the Lake Kivu water level, which reached a maximum of about $50 \mathrm{~cm}$ at the Goma shore, was also observed after the eruption, possibly due to subsidence of the rift system around Goma [2].

\section{INSAR DATA}

The event was captured by InSAR data acquired in three different modes: data from the ERS-2 satellite were acquired along ascending orbits, and data from the RADARSAT-1 satellite were acquired along ascending and descending orbits. The acquisition times of the various interferograms indicate that all the observed ground deformation took place between January 14 and February 13 [3]. Because they were few compatible ERS data, only five ERS independent interferograms cover the event. Unfortunately, they have large time span, thus their coherence is low. In this study, the most coherent ERS interferogram (Fig.1a) will be used. In addition, one ascending and one descending RADARSAT interferogram in ST6 and ST4 modes (Fig.1b-c), respectively, having a short time span, and therefore better coherence than the ERS ascending interferograms, are also available.

InSAR data associated with this eruption show complex ground displacements, with several overlapping fringes patterns, probably associated to a combination of sources of magmatic and regional tectonic origins. The signal observed in A (Fig.1a) corresponds to the compaction of a well-known Nyamulagira lava flows pile (from the 1958, 1967, 1980, 1991-93 eruptions). It is only clearly visible on the ERS interferogram due to its larger time span. The asymmetric fringe patterns observed in $\mathbf{B}, \mathbf{C}$, which are clearly seen in the three modes, are related to the injection of the dike which fed the 2002 eruption. Range changes are opposite for the descending and the ascending modes. In the Goma area, D shows line-of-sight (LOS) range increase in the three modes, with five fringes in ascending modes indicating about 15 centimeters of LOS range increase. In the ST4 RADARSAT descending mode (Fig.1c), the $\mathbf{F}$ signal corresponds to a small range decrease of about two fringes. This signal is not visible on the ascending ERS and RADARSAT modes. Several fringes, indicating a range increase towards the North and Nyamulagira volcano, in area $\mathbf{E}$ are visible in the ascending modes. The signal is possibly linked to the high seismic activity recorded on the western part of the rift during the eruption. This signal is not visible in the descending mode. Small atmospheric or orbital errors are also possible and these plausible sources of LOS changes still under investigations. Heights of ambiguity ( $h a$ ) characterizing the three interferograms are given in Fig.1.: $h a$ characterizes the sensitivity of the interferogram to errors in the DEM: a DEM error of $h a$ would result in a fringe in the interferogram. As the amplitude of signal $\mathbf{E}$ is independent from ha, we can conclude that signal $\mathbf{E}$ is not caused by an error in the DEM.

\section{MODELING METHOD}

The numerical method used to model the InSAR displacements is a 3D Mixed Boundary Element Method [4] which takes into account realistic topographies as well as any number and geometry of faults 

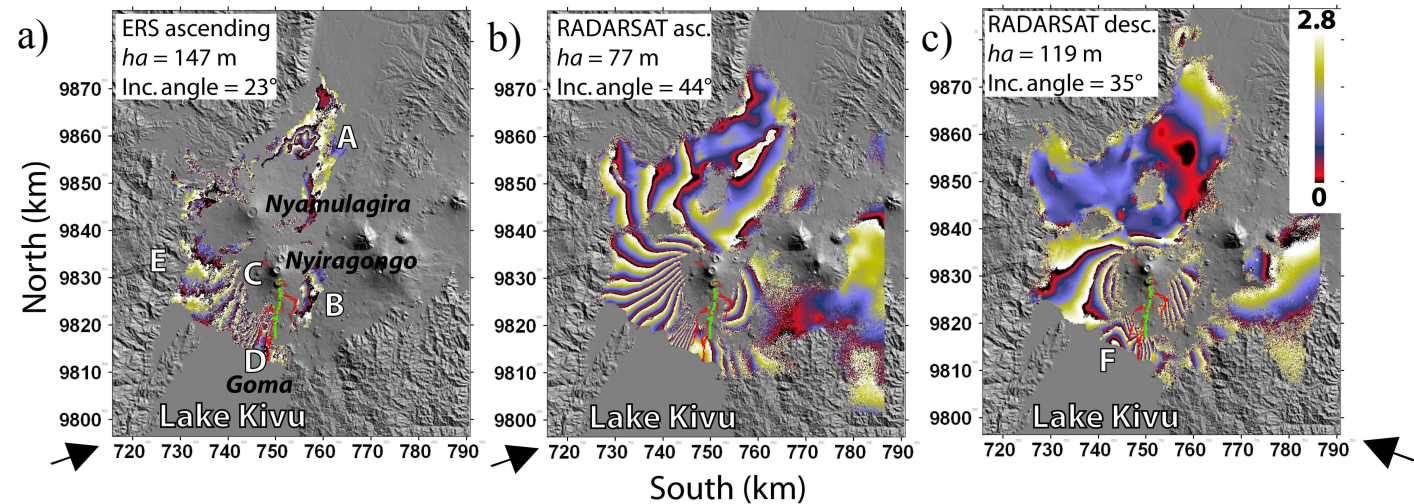

Fig. 1: The three interferograms considered in this study. One color cycle represents a $2.8 \mathrm{~cm}$ satellite-ground range change with positive fringe (red-blue-yellow) corresponding to positive range. Black arrows show LOS vector direction. Areas with incoherent interferometric signals have been masked. The 2002 lava flows are shown in red and eruptive fissures are drawn in green. See the text for the interpretations of signals referred to as A, B, C, D, E and F. a) ERS-2: 6 September $00-3$ July 02. b) RADARSAT-1, ST6 mode: 31 December 01 - 17 February 02. c) RADARSAT-1, ST4 mode: 21 December 01 - 03 March 02.

and pressure sources. This method is combined with a near neighbourhood inversion algorithm [5] to determine the most likely sources parameters. The medium is assumed linearly elastic, homogeneous and isotropic. Boundary conditions are tractions, they are null on the ground surface and equal to constant overpressures for dikes and constant shear stress drops for faults. In order to find the models that best explain the observed data, a misfit function is defined, which quantifies the discrepancy between observed and modeled displacements. It is written as [6]:

$$
\chi^{2}=\left(\mathbf{u}_{\mathbf{o}}-\mathbf{u}_{\mathbf{c}}\right)^{T} C_{d}^{-1}\left(\mathbf{u}_{\mathbf{o}}-\mathbf{u}_{\mathbf{c}}\right)(1)
$$

Where $\mathbf{u}_{\mathbf{o}}$ and $\mathbf{u}_{\mathbf{c}}$ are vectors of observed and modeled LOS displacements, respectively, and $C_{d}$ is a full covariance matrix which takes the data noise correlation as well as the modeling uncertainties into account. In order to make the misfit computation numerically manageable vectors of observed and modeled displacements $\mathbf{u}_{\mathbf{0}}$ and $\mathbf{u}_{\mathbf{c}}$ are constructed by subsampling the observed and modeled LOS displacements at the same points. The near neighborhood algorithm searches for models that minimize the misfit within predefined model parameter bounds. The inversion has two stages: search and appraisal. The search stage will lead to a best fit model. The appraisal stage [7] involves calculations of marginal probability density functions using misfit values calculated during the search stage. It allows estimation of several model statistical characteristics such as the mean model, confidence intervals, posterior model covariance matrices, resolution matrices, or marginal posterior probability density functions (PPD).

The relevance of inverting for different combination of sources - a subvertical dike, a dike next to a deflating reservoir and a dike next to a west dipping normal fault - is studied using synthetic tests. We also investigate the influence of InSAR geometries combinations on the models determination. Synthetic interferograms are computed by adding LOS modeled displacements corresponding to the tested sources to noise with the same statistical characteristics as the InSAR data. The noise characteristics of the InSAR data are determined by masking the deformation signal out of each studied interferograms. Assuming the noise is randomly distributed, an autocorrelation function is computed for each of the three interferograms. The autocorrelations corresponding to each interferogram are further approximated by an exponential function. This function is used to compute the noise that should be added to the synthetic interferograms.

\section{SYNTHETIC TESTS RESULTS}

Important features for the different synthetic tests are shown in table 1. The misfit decreases when increasing the number of inverted SAR geometries. A parameter is considered to be well constrained by the inversion when the mean and best fit (max PPD) model are very close to the synthetic model.

\subsection{Single dike}

Following Fukushima et al. [6], six parameters were used to characterizing the dike geometry (Fig.4a) and overpressure. Approximately 10,000 MBEM models are needed to get inversion convergence with three InSAR geometries. We find that with one, two and three InSAR geometries, both the best fit and the mean model parameters are within the $95 \%$ confidence intervals. Synthetic tests also show that when increasing the number of InSAR geometries from one (ERS) to two (ERS+ST4) and to three (ERS+ST4+ST6), confidence intervals become smaller. Parameter shear (Fig.2) is the least well retrieved, but it is still located within the confidence intervals. This probably comes from the fact that, for the 2002 Nyiragongo eruption the a priori dike model has a large length to height ratio, so that variations in the shear parameter have a negligible influence on the displacement field.

\subsection{Multiple-source: dike and normal fault}

Nine parameters were considered to characterize the dike and fault geometries. An overpressure and a shear stress drop were also determined for the dike and the fault, respectively, so that a total of eleven parameters were considered in the inversions About 20,000 
MBEM models are needed to get inversion convergence with three InSAR geometries. Similarly than for the single dike inversion, we find that whether one, two or three InSAR geometries are considered in the inversions, both the best fit and the mean model parameters are within the $95 \%$ confidence intervals. The least well resolved parameters are the shear stress drop, the height and middle point top side and elevation of the fault. This can be explained by the fact that trade-offs exist between the shear stress drop applied to the fault and its area. However, even when inverting one InSAR geometry, confidence intervals are small and the results are satisfactorily.

\subsection{Multiple-source: dike and deflating ellipse}

Ten parameters were considered for characterizing the dike and ellipsoidal source geometries. Overpressures were also determined for the dike, and the ellipse, making a total of twelve parameters to determine. Again, for the different InSAR geometries inverted, the best fit and mean models are within the confidence intervals. Increasing the number of SAR geometries in this case notably improves the best model and convergence speed. With three SAR geometries, the number of forward models needed for the inversions to converge is reduced by $60 \%$ (table 1 ).

\begin{tabular}{ccccccc}
\hline & \multicolumn{2}{c}{ Single dike } & \multicolumn{2}{c}{ Dike +fault } & \multicolumn{2}{c}{ Dike +ellipse } \\
\hline & $\begin{array}{c}\text { mod } \\
n^{\circ}\end{array}$ & misfit & $\begin{array}{c}\text { mod } \\
n^{\circ}\end{array}$ & misfit & $\begin{array}{c}\text { mod } \\
n^{\circ}\end{array}$ & misfit \\
\hline $\begin{array}{c}1 \\
\text { geom. }\end{array}$ & 3534 & 53.3 & 34373 & 51.2 & 39790 & 46.2 \\
2 & 8439 & 37 & 18371 & 38.1 & 27523 & 45.9 \\
$\begin{array}{c}\text { geom. } \\
3\end{array}$ & 11691 & 32.9 & 20476 & 30.4 & 17701 & 37 \\
geom. & & & & & &
\end{tabular}

Table 1: Overview of some synthetic tests results with: 1 geom.: ERS only. 2 geom.: ERS and RADARSAT ST4. 3 geom.: ERS, RADARSAT ST4 and ST6 inverted. $\bmod n^{\circ}$ is the number of forward MBEM models calculated before convergence of the algorithm. The misfit given here is the misfit defined in the formula (1) normalized respect to maximum misfit value and expressed in percent.

\section{MODELING RESULTS}

The position of the 2002 eruptive fissure is known and preliminary inversions with ERS data only [3] showed that part of the InSAR data, close to eruptive fissure, can be explained with a dike connected to the fissure. The three InSAR data sets available for the eruption are conjointly inverted. InSAR data that are assumed not to be generated by the dike are masked out. The best fit model (Fig.3) obtained corresponds to a subvertical dike, extending down to a few $\mathrm{km}$ (Fig.4b-c). The dike obtained inverting the three dataset leads to an area of $1.3 \times 10^{8} \mathrm{~m}^{2}$, which is $48 \%$ larger than a previous study where only the ERS data set was inverted [3]. The dike overpressure is low, $0.23 \mathrm{MPa}$. Both the quasi vertical dike dip and the small overpressure are consistent with the extensional rifting context. a) $P_{0}(\mathrm{MPa})$

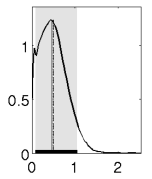

1 geom.: ERS

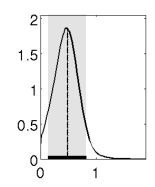

$$
3 \text { geom.: ERS }
$$$$
+S T 4+S T 6
$$

b) Shear $\left(^{\circ}\right)$
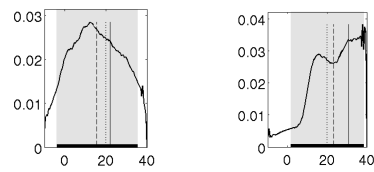

3 geom.: ERS

+ ST4 + ST6
1 geom.: ERS

Fig.2: PPDs obtained for two parameters from synthetic test computed assuming the source is a single dike. a) The overpressure is a well constrained parameter. Increasing the number of geometries tightens the PPD curve and narrows the $95 \%$ confidence intervals represented by the black bold line in the bottom and are grey shaded. b) Parameter Shear, corresponding to the angle between the dike mediane and the maximum gradient, is not well constrained by the inversion even when increasing the number of geometries.
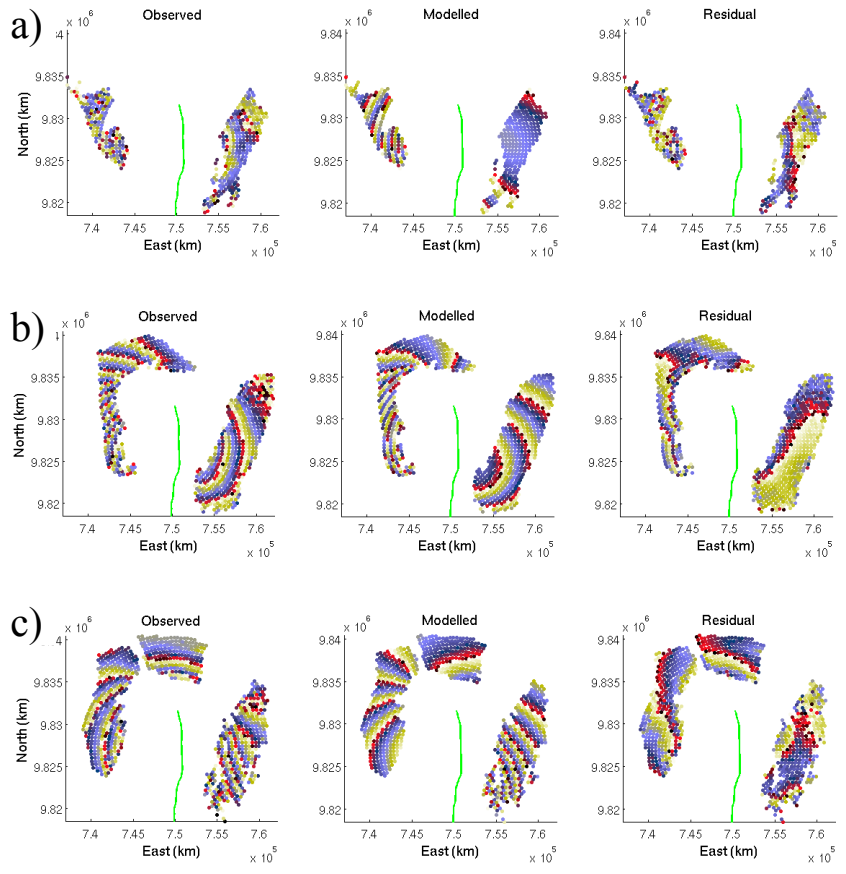

Fig.3: Observed (left) - modeled (center) and residuals (right) interferograms at subsampled data points obtained from a simultaneous inversion of the three SAR geometries considering a single dike: a) ERS data, b) RADARSAT ascending (ST6), and c) RADARSAT descending (ST4) data. The dike is connected to the ground surface at the location of the eruptive fissure represented in green. 


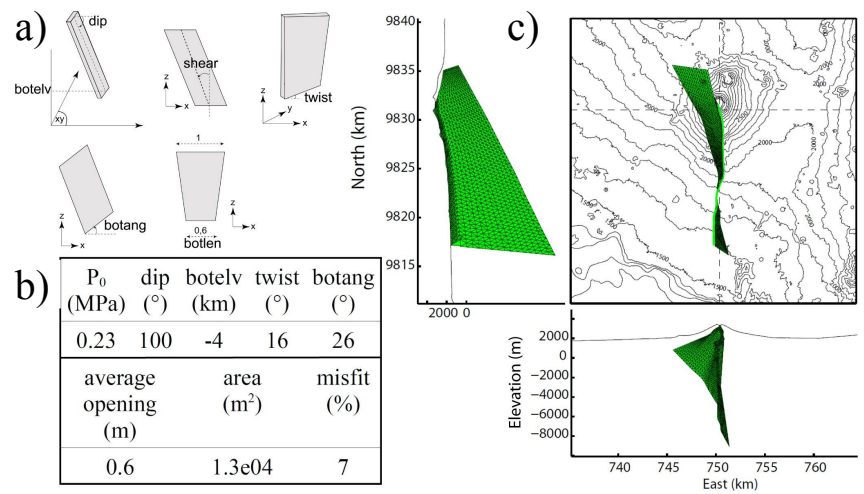

Fig.4: a) Description of the six geometrical dike parameters, b) best fit dike model parameters values (shear fixed to $0^{\circ}$ ), and c) best fit dike model geometry.

The modeling of remaining parts of the three InSAR data sets is still underway. Preliminary inversions of only the ERS data [3] showed that, at least, one other deformation source, most likely a normal fault, is needed to explain the signal in the Goma area. The western part of the interferograms needs to be modeled by a third source. Preliminary inversions show that a normal fault, possibly associated with the border fault of the EAR, could account for this part of the InSAR signal.

\section{CONCLUSIONS}

Inversions of synthetic tests realized for several possible combinations of sources showed that with one, two and three InSAR geometry, the best fit and mean model were within the confidence intervals, whether the displacement sources are a single dike, a dike and a west-dipping normal fault or a dike and an ellipsoidal source. Increasing the number of InSAR geometries makes the confidence intervals smaller and the inversions generally faster.

At this stage of the study, only the displacements close to the eruptive fissure were considered and a single dike model was assumed. The best-fit dike obtained inverting the three InSAR geometries has a dip and overpressure of the dike is consistent with extensional rifting context. The dike area is about $40 \%$ larger than the one obtained in previous studies when only the ERS data were inverted. This shows the importance of using several InSAR geometries.

\section{ACKNOWLEDGMENTS}

RADARSAT-1 data are provided by Canadian Space Agency and Alaska Satellite Facility. ERS data are provided in the frame of ESA Cat-1 project nr 3224. Precise orbits are provided by the Delft Institute of Earth Observation and Space Systems (DEOS) and ESA. ERS interferograms are computed with the DORIS open source software (TUDelft). Phase data are unwrapped using SNAPHU. Srtm digital elevation models are provided by USGS.

\section{REFERENCES}

[1] Ebinger C.J et Furman T., Geodynamical setting of the Virunga volcanic province, East Africa, In : Acta Vulcanologica, The January 2002 eruption of Nyiragongo volcano and the socioeconomical impact, Vol. 14 (1-2) et vol. 15 (1-2), Istituti editorali e poligrafici internazionali, Pisa-Roma, 9-16, 2004.

[2] Komorowski J-C et al., The January 2002 flank eruption of Nyiragongo volcano (Democratic Republic of Congo) : Chronology, evidence for a tectonic rift trigger, and impact of lava flows on the city of Goma, In : Acta Vulcanologica, The January 2002 eruption of Nyiragongo volcano and the socio-economical impact, Vol. 14 (1-2) et vol. 15 (1-2), Istituti editorali e poligrafici internazionali, Pisa-Roma, 27-62, 2004.

[3] C. Wauthier, V. Cayol, F. Kervyn, N. d'Oreye, "Modeling of InSAR displacements related with the January 2002 eruption of Nyiragongo volcano, Proc. of the 26th ECGS Workshop, Active Volcanism \& Continental Rifting with special focus on the Virunga (North Kivu, DRC), Luxembourg, November 19-21, 2007, In: ECGS Blue Book (submitted).

[4] V. Cayol, F.H. Cornet, "3D mixed boundary elements for elastostatic deformations fields analysis", Int. J. Rock Mech. Min. Sci. Geomech. Abstr., 34, 275-287, 1997.

[5] M. Sambridge, 1999a, Geophysical inversion with a neighbourhood algorithm - I. Searching a parameter space, Geophys. J. Int., 138, 479-494.

[6] Y. Fukushima, V. Cayol, P.Durand, "Finding realistic dike models from interferometric synthetic aperture radar data: The February 2000 eruption at Piton de la Fournaise," Journal Geoph. Res., VOL. 110, B03206, 2005.

[7] M. Sambridge, 1999b, Geophysical inversion with a neighbourhood algorithm - II. Appraising the ensemble, Geophys. J. Int., 138, 727-746. 